\title{
“¿YO SOY TU PADRE?": REFLEXIONES SOBRE LA REGULACIÓN ACTUAL DE LA PATERNIDAD EXTRAMATRIMONIAL
}

\author{
AM I YOUR FATHER? REFLECTIONS ABOUT \\ EXTRAMARITAL PATERNITY REGULATION
}

\section{Resumen}

Beatriz May Ling Ramírez Huaroto ${ }^{1}$

La regulación de la filiación extramatrimonial es una de las más debatidas del derecho de familia peruano. Luego de varios casos mediáticos que evidenciaron las dificultades que se desprendían de la regulación original del Código Civil, se hicieron significativos cambios. En 2017, a casi 5 años de la última modificación, se emprendieron las últimas reformas. El trabajo repasa la evolución de la regulación de la declaración judicial de paternidad y revisa los desafíos.

Palabras Clave:Filiación, Paternidad, DerechodeFamilia,Constitucionalidad.

\section{Abstract}

The regulation of extramarital parenthood is one of the most important issues of Peruvian family law. After several media cases that evidenced the difficulties that stemmed from the original regulation of the Civil Code, significant changes were made. In 2017, almost 5 years after the last modification, the last reforms were undertaken. The work reviews the evolution of the regulation of the judicial declaration of paternity and review of the challenges.

Keywords: Parenthood, Paternity, Family Law, Constitutionality.

Abogada, Magister en Derecho Constitucional y Doctoranda en Derecho por la PUCP, con estudios intensivos de posgrado en Derecho de Familia por la Universidad de Buenos Aires. Docente de la Universidad Nacional Mayor de San Marcos y de la Maestría con mención en Derecho de Familia de la UNIFÉ. 


\section{INTRODUCCIÓN}

El derecho de familia peruano no ha variado significativamente desde su versión original en 1984, salvo lo relacionado a la filiación extramatrimonial. Luego de varios casos mediáticos que evidenciaron las dificultades que se desprendían de la regulación de la paternidad extramatrimonial, se hicieron significativas reformas por medio de las Leyes № 27048 y № 28457. En 2011, con las Leyes $\mathrm{N}^{\circ} 29715$ y N $\mathrm{N}^{\circ} 29821$, se aprobaron dos cambios más al proceso, incluyendo esta última la variación de la carga de la prueba. En 2017 se promulgó la Ley N 30628 que reguló algunos aspectos no previstos previamente y a mediados de 2018 se aprobó a nivel judicial el último formato de acceso a los procesos conforme a las últimas reformas aprobadas. El presente trabajo repasa la evolución expuesta de la regulación de la declaración judicial de paternidad extramatrimonial y revisa los desafíos en la materia.

\section{EL SISTEMA PERUANO DE INVESTIGACIÓN HISTÓRICO DE DECLARACIÓN JUDICIAL DE LA PATERNIDAD.}

El artículo $402^{\circ}$ del Código Civil peruano es la norma que regula las situaciones en las que se puede hacer un juicio de reclamación de paternidad si el padre no reconoce voluntariamente a su hija o hijo. Para el entendimiento de esta norma conviene analizar previamente qué tipo de sistema de investigación de la paternidad es el sistema peruano. Existen sistemas prohibitivos y permisivos. Los sistemas prohibitivos de investigación de paternidad, imagen del Código Civil francés napoleónico de 1804, fueron desplazados en el siglo XX con el catálogo de derechos humanos (Varsi 1999: p. 51-52) $)^{2}$. Los sistemas permisivos de filiación extramatrimonial pueden ser de cerrados, abiertos o mixtos. Un sistema cerrado restringe la investigación de la paternidad a una lista de causales, uno abierto la permite libremente, y uno mixto contempla causales más un supuesto de investigación libre ${ }^{3}$. En los sistemas cerrados y mixtos las causales son supuestos que cumplen una doble función: en primer lugar, son los únicos casos en los que se admite indagar la paternidad y, en segunda instancia, son presunciones legales iuris tantum sobre la misma que la parte demandante deberá acreditar de manera debida y con todos los medios probatorios a su alcance y que el demandado puede contradecir (Varsi 1999: p. 56-57).

\footnotetext{
Cornejo Chávez plantea que, aunque la investigación de la paternidad suele ser considerada como una conquista moderna en realidad durante el pasado se han sucedido periodos en los que se ha admitido y en los que se ha prohibido (1999: p. 471).

Nuestra clasificación difiere en la definición de las categorías que con términos similares emplea Enrique Varsi (1999: p. 59-61).
} 
El sistema peruano de investigación de paternidad ha sido permisivo, pero cerrado desde el Código Civil de 1852; también en el Código de 1936 y en la redacción original del Código de 1984 que estuvo vigente hasta el año 1999.

En un sistema cerrado de investigación de la paternidad, como el vigente en el Código Civil de 1936 y en la redacción original del Código Civil de 1984, sólo los supuestos contemplados en la norma son permitidos para activar procesos de paternidad extramatrimonial. En ese sentido Cornejo Chávez, ponente del Libro de Familia del Código Civil de 1984, señalaba expresamente que fuera de los cinco casos que la norma enumera taxativamente el artículo, no había ninguno, dentro de nuestro ordenamiento legal, en que pudiera plantearse la demanda de investigación judicial de la paternidad (1999: p. 486). Este criterio fue cuestionado en el devenir de la vigencia del Código y, aunque con pronunciamientos judiciales disidentes del mismo ${ }^{4}$, existía consenso en que "la naturaleza que se le daba al elenco de supuestos de hecho contenidos en el art. $402^{\circ}$ del Código Civil era de una cláusula cerrada o numerus clausus, es decir, basada en el principio de tipicidad: sólo se podían amparar las causales ahí previstas y no otras" (Espinoza 2005: p. 381).

Se desprende de esto que, en una norma de este tipo no se consideran todas las posibilidades en que se puede generar una paternidad (Varsi 1999: p. 55). Existen casos claramente excluidos: las maternidades derivadas de relaciones sexuales esporádicas o aquellas que son producto de relaciones sentimentales que no encajan en la definición de un concubinato (por ejemplo, las relaciones entre enamorados/as o las relaciones de amantes). El caso bajo análisis cuadra en uno los supuestos excluidos.

Una regulación restrictiva de la investigación de la paternidad matrimonial que excluye relaciones filiales como las discutidas en el expediente bajo análisis, revela un sesgo intencional que excluye supuestos de relaciones afectivas consideradas "moralmente reprochables"

\footnotetext{
Varsi Rospigliosi cita una resolución de 1993 en la que la Corte Suprema de la República consideró que pese a que la acreditación de relaciones sexuales en época contemporánea a la concepción no se había contemplado en el artículo $402^{\circ}$ era deber de los órganos jurisdiccionales declarar la paternidad en virtud de una prueba biológica practicada (1999: p. 225-230). Por su parte, Espinoza Espinoza comenta una resolución similar de la Sala Civil de Corte Superior de Justicia de 1997 (2005: p. 379-380). Sin embargo, soluciones como garantistas de este tipo no mellaban la vigencia de discusión sobre el tema y así, la controversia acerca de si podía considerarse la prueba genética como un supuesto independiente para la admisibilidad de la demanda de investigación de la paternidad se plasmó en el Acuerdo № 4 de la Sesión Plenaria del Pleno Jurisdiccional Nacional de Familia 1998 en donde se señaló que "Sí puede considerarse como un supuesto independiente la aprobación de paternidad para la admisibilidad de la demanda" y que "La Ley Civil no restringe la investigación de paternidad extra-matrimonial, aunque presenta situaciones legales contrapuestas que, sin embargo, el juzgador debe superar, pues la parte accionante puede probar su acierto en el proceso, si las pruebas que aportó así lo acreditan. Por otro lado, podría entenderse que la limitación se daría en la práctica por la dificultad económica de quien solicita la prueba o del obligado a asumir el pago." Disponible en <http://historico.pj.gob.pe/CorteSuprema/documentos/..\%5C..\%5CCorteSuprema\%5Ccij\%5Cdocumentos\%5CPleno_Jur_Nac_1998.pdf>. Consulta: 31 de agosto de 2018.
} 
(Fernández 2011: p. 196-197). Este sesgo tiene repercusiones en los derechos fundamentales de las hijas e hijos cuya filiación paterna no está determinada y, además, es una forma de discriminación en razón del sistema sexo-género en dos sentidos: en primer lugar porque en las causales contempladas es la conducta del supuesto padre la piedra angular de habilitación del proceso $\mathrm{y}$, complementariamente, por las consecuencias que tiene para las mujeres un sistema cerrado de investigación de la paternidad extramatrimonial que determinan que sólo ellas asumirán las obligaciones materiales respecto de sus hijas e hijos pues son las únicas con filiación legalmente establecida (Ramírez 2009: p. 2, 15; Fernández 2011: p. 196-197).

\section{LA APERTURA DEL SISTEMA DE CARA A LA GENÉTICA}

La primera modificación al régimen normativo de la declaración de paternidad se dio con la Ley № 27048, publicada el 6 de enero de 1999. La dación de esta norma tiene sus antecedentes en el contexto de la difusión en un programa televisivo de una denuncia que involucraba a dos personajes públicos: la bailarina Rubí Berrocal señaló públicamente que el periodista Alejandro Guerrero se negaba a reconocer la paternidad de su hija nacida en marzo de 1998 como producto de una relación sentimental extramatrimonial entre ambos. Entre otras reformas, la mencionada ley abrió expresamente el sistema de investigación de la paternidad a los casos en que pudiese acreditarse el vínculo biológico por medio de la prueba de ADN y lo hizo regulando esta posibilidad como un supuesto independiente de las causales históricamente reguladas (Varsi 1999: p. 93).

Aún durante la vigencia de esta norma se continuó discutiendo si la sola invocación a los resultados de la prueba de ADN habilitaba por sí misma que pudiera presentarse una declaración judicial de paternidad, si es que la paternidad no encajaba en alguno de los cinco supuestos del artículo $402^{\circ}$ del Código Civil ${ }^{5}$.

La Ley № 27048 "democratizó" el acceso a la justicia para la garantía de los derechos de mujeres, hijas e hijos relacionados asociados a la declaración legal de la filiación paterna pues varió la configuración del sistema nacional de investigación de la paternidad para convertirlo en uno de carácter mixto por yuxtaposición en tanto coexisten las causales de investigación de la paternidad propias de un sistema cerrado (incisos 1 al 5) con un supuesto

\footnotetext{
Esta continuidad del debate se ve plasmada en el Acuerdo № 5 de la Sesión Plenaria del Pleno Jurisdiccional Nacional de Familia 1999 en donde a la pregunta de si los/las jueces y juezas debían considerar al ADN como una prueba o como una causal de la filiación: se señaló que "el Juez debe considerar al ADN como una prueba". Disponible en <http://historico.pj.gob.pe/CorteSuprema/documentos/..\%5C..\%5CCorteSuprema $\% 5$ Ccij $\% 5 C$ documentos\%5CPleno_Jur_Nac_1999.pdf $>$. Consulta: 31 de agosto de 2018.
} 
de investigación libre (inciso 6). El caso de Rubí Berrocal contra Alejandro Guerrero $^{6}$ resultó emblemático de maternidades generadas en relaciones sentimentales extramatrimoniales que no encontraban habilitación legal expresa para iniciar reclamaciones de paternidad.

Por otro lado, en la medida que las causales históricas se consideraban presunciones legales iuris tantum sobre la paternidad que el demandado podía contradecir (Varsi 1999: p. 56-57; Cornejo 1999: p. 476), la redacción original del artículo $413^{\circ}$ del Código Civil sólo admitía la prueba negativa de los grupos sanguíneos $\mathrm{u}$ otras de validez científica en los procesos de declaración judicial de paternidad extramatrimonial; esto significaba que la admisión de las pruebas biológicas estaba limitada a ser un medio del demandado que le permitía contradecir las presunciones sólo los procesos iniciados al amparo del artículo 402․ Pese a que este criterio era discutido en instancias judiciales ${ }^{7}$, no fue sino hasta la emisión de la Ley № 27048 en que se permitió la utilización de las pruebas biológicas en todo tipo de acciones de filiación de paternidad y maternidad, tanto de emplazamiento como desplazamiento (Varsi 1999: p. 93).

\section{UNA NUEVA REGULACIÓN Y UNA VÍA PROCESAL ESPECÍFICA PARA EL SUPUESTO DE DECLARACIÓN JUDICIAL DE PATERNIDAD BASADO EN PRUEBAS BIOLÓGICAS}

La segunda modificación importante al sistema se produjo con la Ley № 28457, publicada el 8 de enero de 2005. La iniciativa fue producto de los trabajos sobre reformas legislativas impulsados por la CERIAJUS $^{8}$ y resultó de la acumulación de varios proyectos de ley presentados entre julio de 2001 y septiembre de 2004 .

La ley modificó la regulación de uno de los supuestos para la determinación de la declaración judicial de la paternidad extramatrimonial: la acreditación de la filiación biológica, y a la vez creó un mecanismo

\footnotetext{
Meses después de la denuncia pública Rubí Berrocal interpuso una demanda de declaración judicial de paternidad. Después de un largo proceso judicial, y gracias a las reformas introducidas por la Ley № 27048 en enero de 1999, el Poder Judicial determinó en diciembre de ese año que Alejandro Guerrero era padre de la hija de ambos pues se negó constante e injustificadamente a someterse a la prueba de ADN. El proceso judicial duró tres años pues la apelación se resolvió en junio de 2000 (Espinoza 2005: p. 429-445).

7 Esta afirmación se corrobora con el hecho de que la pertinencia de las pruebas de ADN en los procesos de filiación paterna extramatrimonial fue materia de revisión en el Acuerdo № 11 de la Sesión Plenaria del Pleno Jurisdiccional Nacional de Familia 1997: "Por consenso se estableció que sí es procedente ordenar la prueba del ADN en los procesos de declaración de paternidad; sin embargo, no debe exigirse su cumplimiento contra la voluntad del llamado a someterse a dicha prueba, pues ello atentaría contra su libertad individual. En los casos de negarse la parte, esta conducta será apreciada por el Juez, pudiendo extraer conclusiones negativas para el que se opuso, de conformidad con el art. 282 del CPC." Disponible en <http://historico.pj.gob.pe/CorteSuprema/documentos/..\%5C..\%5CCorteSuprema\%5Ccij\%5Cdocumentos\%5CPleno Jur Nac 1997.pdf>.Consulta: 31 de agosto de 2018.

8 Comisión Especial para la Reforma Integral de la Administración de Justicia. Plan Nacional de Reforma Integral de la Administración de Justicia. Lima, mayo de 2004.
} 
procesal especial para tramitar esta pretensión. Lo primero se plasma en que, en adelante, la falta de contestación de una demanda de filiación o la negativa a realizarse la prueba de $\mathrm{ADN}$ son elementos suficientes para declarar la paternidad. En tal sentido, si un demandado no se presenta al proceso judicial o contradice la paternidad en el proceso sin realizarse la prueba de ADN entonces es declarado padre. Lo segundo se refleja en que las reclamaciones de paternidad basadas en el inciso 6) del artículo $402^{\circ}$ del Código Civil se tramitan en una vía procesal específica y sumamente célere.

La determinación de la declaración de paternidad ante la falta de oposición del demandado y, sobre todo, ante la negativa a someterse a la prueba de ADN tuvo su base en las constantes negativas injustificadas de los supuestos padres que repercutían en que -en buena parte de los casos- juezas y jueces no emplazarán la paternidad, sino que se limitarán a otorgar una pensión de alimentos al amparo del artículo $415^{\circ}$. Uno de los casos públicos que puso de relieve este punto fue el de Lucrecia Orozco contra Alejandro Toledo?.

Los cambios materiales y procesales incluidos por la Ley № 28457 acercaron en la práctica el sistema peruano de investigación de la paternidad a uno de tipo abierto, si bien en la regulación legal se trata de un sistema mixto por yuxtaposición como se ha indicado previamente. Esta afirmación se fundamenta en que existen dos vías paralelas para la reclamación de la paternidad por vía judicial: una para los supuestos de los incisos 1 al 5 del artículo $402^{\circ}$ y otra para los casos del inciso 6 del artículo $402^{\circ}$, con ostensibles diferencias de tiempo y formalidades entre ambas (todas a favor de la nueva causal de libre investigación de paternidad). En la práctica han caído en desuso las demandas basadas en las causales históricas para dar protagonismo exclusivo a la nueva causal acompañada de su regulación especial.

Las ventajas de la Ley № 28457 pueden apreciarse en el siguiente cuadro comparativo:

\footnotetext{
En el caso de Lucrecia Orozco contra Alejandro Toledo éste se negó desde 1987 a reconocer a la hija de ambos. La Sra. Orozco planteó tres procesos de reclamación de paternidad -el primero iniciado en 1989 y el último en 1994- y en todos los procesos su pretensión fue desestimada porque no acreditaba ninguno de los supuestos recogidos en el artículo $402^{\circ}$ : su relación con Toledo fue extramatrimonial (él era casado) y no hubo convivencia entre ambos. Hay que anotar que en el proceso iniciado en 1994 el juzgado contaba con un examen de histocompatibilidad sanguínea favorable a la paternidad de Toledo y, por ello, ordenó que se realizara la prueba de ADN para tener mayor confiabilidad en los resultados. El demandado, Alejandro Toledo, no asistió las dos veces que fue citado para realizarse la prueba; pese a esto, la demandante perdió el proceso y la paternidad no se declaró. En el año 2001, la Sra. Orozco inició un nuevo proceso judicial al amparo de las reformas introducidas en el año 1999 por la Ley № 27048 antes mencionada: demandó la paternidad por la nueva causal del artículo $402^{\circ}$ del Código Civil, la acreditación de vínculo parental a través de la prueba del ADN lo que suscitó un debate sobre la cosa juzgada. En este proceso, Toledo se negó también a practicarse el ADN, pero por presión pública accedió a efectuar el reconocimiento; con eso se dio fin al proceso judicial. Cada uno de los procesos judiciales incoados por la Sra. Orozco en representación de su hija duró aproximadamente dos años (Espinoza 2002: p. 29-40).
} 


\begin{tabular}{|c|c|c|}
\hline & $\begin{array}{c}\text { Demanda basada en los incisos } \\
1 \text { al } 5 \text { del artículo } 402^{\circ} \text { del } \\
\text { Código Civil }\end{array}$ & $\begin{array}{l}\text { Demanda basada en el inciso del } \\
\text { artículo } 402^{\circ} \text { del Código Civil }\end{array}$ \\
\hline Tipo de proceso & Proceso de conocimiento & Proceso especial \\
\hline $\begin{array}{l}\text { Duración } \\
\text { aproximada }\end{array}$ & 2 años & 6 meses \\
\hline $\begin{array}{l}\text { Juzgados } \\
\text { competentes }\end{array}$ & Juzgados de Familia o Mixtos & Juzgados de Paz Letrado \\
\hline $\begin{array}{l}\text { Pruebas } \\
\text { requeridas }\end{array}$ & $\begin{array}{c}\text { Variable dependiendo de la causal } \\
\text { alegada (puede incluirse la prueba } \\
\text { de ADN u otra de igual o mayor } \\
\text { certeza) }\end{array}$ & Prueba de ADN \\
\hline $\begin{array}{l}\text { Falta de } \\
\text { oposición del } \\
\text { demandado }\end{array}$ & $\begin{array}{c}\text { Declaración en rebeldía según el } \\
\text { artículo } 458^{\circ} \text { del Código Procesal } \\
\text { Civil }\end{array}$ & $\begin{array}{c}\text { Genera automáticamente declaración } \\
\text { judicial de paternidad } \\
\text { extramatrimonial }\end{array}$ \\
\hline $\begin{array}{l}\text { Falta de } \\
\text { sometimiento del } \\
\text { demandado a la } \\
\text { prueba de ADN }\end{array}$ & $\begin{array}{c}\text { Apreciable por el órgano } \\
\text { jurisdiccional según el artículo } \\
282^{\circ} \text { del Código Procesal Civil } \\
\text { junto con otros elementos } \\
\text { probatorios }\end{array}$ & $\begin{array}{c}\text { Genera automáticamente declaración } \\
\text { judicial de paternidad } \\
\text { extramatrimonial }\end{array}$ \\
\hline
\end{tabular}

Los cambios introducidos por la Ley № 28457 fueron materia de una ardua discusión jurídica. Las reformas que se introdujeron para una mayor protección a los derechos de la parte demandante fueron objeto de fuertes críticas desde sectores de la doctrina ${ }^{10}$ que se plasmaron en algunas sentencias en las que se declaró inaplicable la norma ${ }^{11}$ : el argumento central era que las reformas introducidas afectaban diferentes derechos fundamentales de los presuntos padres.

De los modelos de control constitucional (Landa 2003: p. 41-69; Fernández Rodríguez 2007: p. 71-79), el ordenamiento jurídico peruano acoge el control concentrado y el control difuso: el control abstracto se da cuando se analiza la compatibilidad lógica entre dos normas, la Constitución y la ley impugnada, al margen de un caso concreto, y en nuestro sistema está a cargo del Tribunal Constitucional; y el control difuso que se produce cuando ese análisis tiene como referente un caso concreto, lo que implica tener en cuenta las circunstancias del mismo, y en nuestro sistema está a cargo de los órganos de la justicia ordinaria (Fernández Rodríguez 2007: p. 73). Este último, tiene

10 Entre los trabajos contrarios destacan Plácido (2005), Ariano (2005) y Espinoza (2010). En sentido favorable a la constitucionalidad de la norma, Varsi (2006 y 2007) y Ramírez (2007).

11 Por ejemplo, sentencia en el Expediente 363-05 del Primer Juzgado de Puente Piedra, Santa Rosa y Ancón (28 de septiembre de 2005) y sentencia en el Expediente 2005-1785 del Primer Juzgado de Paz Letrado del Módulo Básico de Justicia de Condevilla (18 de mayo de 2007). 
sustento normativo en el artículo 51ํㅡ y el artículo $138^{\circ}$ de la Constitución; en sentido semejante se pronuncia también el artículo VI del Título Preliminar del Código Procesal Constitucional.

Un caso de inaplicación por control difuso sobre la Ley № 28457 llegó a conocimiento de la Corte Suprema ${ }^{12}$. La jueza del Primer Juzgado Mixto del Módulo Básico de Justicia de Condevilla declaró inconstitucional e inaplicable la ley por considerar que lesionaba los derechos constitucionales de libertad y debido proceso del demandado, bajo los siguientes argumentos:

1) Vulnera el derecho a la libertad la configuración del proceso plasmado en el segundo artículo de la Ley № 28457 que establece que el demandado debe efectuarse la prueba de ADN dentro de los diez días de notificado como única posibilidad de oposición a la declaración judicial de la paternidad, pues implica un mecanismo de coacción del poder estatal contra la parte demandada.

2) Vulnera el debido proceso que la configuración legal del proceso coloque en una situación de desigualdad a las partes pues el órgano jurisdiccional emite una resolución declarando la filiación demandada sin que se exija a la demandante la presentación ni la calificación ni actuación de medios probatorios que corroboren su sindicación.

3) Vulnera el debido proceso que la configuración legal del proceso limite el uso de medios probatorios por el demandado pues la única prueba admitida es la de ADN, que carece de regulación para su realización en el país con estándares de calidad.

En aplicación del artículo $14^{\circ}$ de la Ley Orgánica del Poder Judicial, la Corte Suprema conoció la causa y desaprobó la resolución de control difuso emitida por la jueza del MBJ de Condevilla indicando que la Ley № 28457 no afectaba ni el derecho a la libertad del demandado ni su derecho al debido proceso y que, en el caso debía aplicarse la ponderación de los derechos constitucionales involucrados que incluían el derecho al nombre y el derecho a la identidad personal. Para ello se usaron los siguientes argumentos:

1) No existe vulneración a la libertad -aunque se reconoce que este derecho fundamental puede ser materia de restricciones- en tanto la ley no obliga al demandado a someterse a la prueba de sangre, ni a que se le conduzca de grado o fuerza, por lo que es libre de

12 Resolución en el Expediente № 1699-2007 de la Sala Constitucional y Social de la Corte Suprema de Justicia. 
decidir si concurre a la toma de las muestras para el examen de ADN. Lo que se evalúa es su conducta ante un medio probatorio que resulta determinante, y que daría solución a la litis, y con ello se busca proteger el derecho fundamental a la identidad y al nombre de las /os niñas/os cuya filiación paterna se discute.

2) No hay vulneración al debido proceso porque el demandado tiene la posibilidad de oponerse al mandato de declaración de paternidad y someterse a la prueba del ADN para demostrar su no paternidad.

3) No hay vulneración al debido proceso el hecho que el proceso se base en la prueba del ADN porque es una prueba considerada científicamente determinante para dilucidar la filiación en la medida que otros medios probatorios no asegurarían la resolución del caso con la certeza que ofrece dicha prueba biológica.

\section{LAS ÚLTIMAS REFORMAS AL PROCESO DE FILIACIÓN EXTRA- MATRIMONIAL}

Con la Ley $\mathrm{N}^{\circ}$ 29715, publicada el 22 de junio de 2011, se aprobó la inversión de la carga de la prueba de forma que sea la parte demandada que se opone a la declaración de la paternidad la que asume el pago de la prueba de ADN. Asimismo, se precisó que para efectos de los procesos de declaración judicial de paternidad extramatrimonial "no resulta necesaria la realización de la audiencia especial de ratificación pericial, ni los actos procesales que establece el artículo 265ํํㄹ del Código Procesal Civil”.

Sobre lo primero, algunos autores sostuvieron que con la dación de la Ley № 28457 ya se había producido una inversión en la carga de la prueba en la medida de que, dado que se refería a la primera resolución del juez como un mandato declarativo de la paternidad, era el padre el que debía "demostrar la no vinculación filial imputada por la madre" (Varsi 2006, p. 50$53)^{13}$. No obstante, como se ha planteado con anterioridad, era la demandante quien debía acreditar su afirmación de paternidad lo que se plasmaba en que debía asumir el costo de la prueba: el demandado sólo tenía la obligación de someterse a la misma y, por ello, su negativa a la realización de la prueba, que no le ocasionaba perjuicio alguno, era valorada como suficiente para la declaratoria de la paternidad (Ramírez 2007, p. 16-17).

En un trabajo previo he criticado la solución adoptada por la Ley $\mathrm{N}^{\circ}$ 29715 pues el pago de las pruebas a cargo del demandado se enfrentó a la falta

13 En el mismo sentido, Lloveras \& Orlandi (2007, p. 41) y Liési (2007, p. 75-78). 
de incentivos de esta parte para conseguir el dinero para ello, especialmente en situaciones de pobreza (Ramírez 2011, p. 344). En varios lugares del país, varias causas quedaron pendientes de resolución por meses ante la falta de recursos de los demandados para pagar la prueba de ADN pues, a criterio de un grupo de jueces y juezas de paz letrado, no debía declararse la paternidad si el demandante acreditaba ausencia de suficientes recursos económicos, pues no se trataba de una situación que fuera equivalente a una oposición injustificada a la actividad probatoria. La inversión de la carga de la prueba decretada por medio de la Ley $\mathrm{N}^{\circ} 29715$ omitió la responsabilidad estatal para la garantía del derecho a la identidad, particularmente relevante en casos de personas en situación de pobreza y extrema pobreza (Ramírez 2011, pp. 344-350).

También en 2011, con la Ley Nº 29821 publicada el 28 de diciembre de ese año, se introdujo un cambio al modelo procesal: incorporar como pretensión acumulada a la determinación judicial de la paternidad extramatrimonial, la determinación de los alimentos correspondientes. Para eso se dispuso el traslado de la pretensión alimentaria junto con el mandato de paternidad extramatrimonial, la obligación de la absolución de esta en el plazo de 10 días desde la notificación válida y, en casos de oposición a la pretensión de paternidad, se fijó la convocatoria a una audiencia única a realizarse dentro de los 10 días siguientes para que se haga la toma de muestras para la prueba de ADN y la determinación de los alimentos.

Por último, en 2017 se promulgó la Ley N³0628, publicada el 3 de agosto, por la que se precisaron diferentes aspectos del proceso:

- la posibilidad de que la prueba biológica del $A D N$ se realice con las muestras del padre, madre $u$ otros hijos del demandado en caso el padre no tenga domicilio conocido, sea inubicable o este haya muerto,

- la precisión de que el costo de la prueba es abonado por la parte demandada en la audiencia al laboratorio privado al que se encargue la realización de la prueba, el mismo que deberá estar acreditado conforme a la regulación sanitaria correspondiente para brindar las garantías necesarias,

- la posibilidad de reprogramación de la toma de muestras dentro de los 10 días siguientes, al término del cual de todas formas se declara la paternidad.

- la posibilidad de que la parte demandante pueda asumir, si lo desea, el costo de la prueba en un laboratorio privado, con la regulación de la devolución si el resultado de paternidad es positivo,

- la incorporación de la posibilidad de allanamiento desde la notificación inicial hasta antes de la realización de la prueba de ADN, 
- la exoneración de tasas judiciales en los procesos,

- la exoneración de firma de abogada/o en la demanda.

Por medio de la Resolución Administrativa N ${ }^{\circ}$ 257-2018-CE-PJ, publicada el 12 de septiembre de 2018, se aprobó el último formato de demanda acumulada de filiación judicial de paternidad extramatrimonial y de alimentos para niñas, niños y adolescentes, herramienta para viabilizar el acceso a la justicia conforme a las últimas reformas aprobadas en la materia.

\section{ANÁLISIS DE CONSTITUCIONALIDAD DEL PROCESO JUDI- CIAL DE FILIACIÓN EXTRAMATRIMONIAL}

Realizar un adecuado análisis de constitucionalidad presupone la adecuada identificación de las medidas de intervención en juego. Por intervención debe entenderse toda aquella medida que afecte de manera negativa o desventajosa a una norma o a una posición que pueda adscribirse prima facie al ámbito de protección inicial de un derecho fundamental (Bernal Pulido 2007: p. 663-671). En relación con el proceso judicial de filiación extramatrimonial existen cuatro medidas de intervención sobre las que podría centrarse el análisis de constitucionalidad:

1) La imposición legal de la declaración de la paternidad por el sólo hecho de no oponerse a la demanda en el plazo de diez días, contenida en el artículo $1^{\circ}$ de la Ley № 28457 ;

2) La imposición legal de la declaración de la paternidad por la sola negativa de colaboración con la prueba de $\mathrm{ADN}$ contenida en el artículo $2^{\circ}$ de la Ley № 28457 ;

3) El privilegio de la prueba de $\mathrm{ADN}$ en el proceso especial creado por la Ley № 28457 en desmedro de otros medios probatorios, lo cual se basa también en el artículo $2^{\circ}$ de la norma:

4) El pago de la prueba de ADN está a cargo de la parte que se opone a la declaración de la paternidad, dispuesto en el artículo $2^{\circ}$ de la ley.

Es posición de este trabajo que las cuatro medidas de intervención identificadas en la Ley № 28457 son constitucionales y, para sustentar dicha conclusión, se aplicará en cada caso el principio de proporcionalidad. Este es un criterio estructural para la determinación del contenido de los derechos fundamentales vinculante para el Poder Legislativo, "cumple la función de fundamentar la concreción de normas iusfundamentales adscritas en los casos difíciles" (Bernal Pulido 2007: p. 539). 
En el test de proporcionalidad se analiza, en primer lugar, la idoneidad de la medida, esto es que "toda intervención en los derechos fundamentales debe ser adecuada para contribuir a la obtención de un fin constitucionalmente legítimo" (Bernal Pulido 2007: p. 693). En segundo lugar, se evalúa la necesidad de la medida, lo que significa que para ser constitucional ha de ser "la más benigna con el derecho fundamental intervenido entre todas aquellas que revisten la misma idoneidad para contribuir a alcanzar el objetivo propuesto" (Bernal Pulido 2007: p. 740).

Por último, se realiza el examen de proporcionalidad en sentido estricto o ponderación, definido como la evaluación de que "la importancia de la intervención en el derecho fundamental debe estar justificada por la importancia de la realización del fin perseguido por la intervención legislativa" (Bernal Pulido 2007: p. 763). Esto implica tener presente la estructura de la ponderación que tiene tres elementos: la ley de ponderación, la fórmula del peso y las cargas de argumentación (Bernal 2005, p. 21). La ley de la ponderación prescribe que "cuanto mayor es el grado de la no satisfacción o de afectación de uno de los principios, tanto mayor debe ser la importancia de la satisfacción del otro" (Bernal 2005, p. 22). La fórmula del peso es la que relaciona los pesos abstractos de los principios, su grado de afectación y la seguridad de las premisas empíricas en cada caso (Bernal 2005 , p. 24-25). Por último, las cargas de argumentación son las que "operan cuando existe un empate entre los valores que resultan de la aplicación de la fórmula del peso" (Bernal 2005, p. 26-27).

Respecto de la primera medida de intervención, referida a la imposición legal de la declaración de la paternidad por el sólo hecho de no oponerse a la demanda en el plazo de diez días, la evaluación de la constitucionalidad se centra en si es legítimo que por ley se disponga que pueden extraerse consecuencias jurídicas de la no contradicción, lo que no pasa por considerar al proceso regulado por la Ley $\mathrm{N}^{\mathrm{o}} 28457$ como un proceso monitorio como afirmó cierto sector de la doctrina en su oportunidad (Martel 2005: p. 67-68; Varsi 2006: p. 56-57; Ariano 2005: p. 66).

Extraer consecuencias jurídicas de la omisión de formulación de oposición procesal por parte del demandado tiene como presupuesto que éste no ha ejercido libremente su legítimo derecho de contradicción. En nuestro ordenamiento es válido desprender consecuencias de la conducta procesal de las partes (artículo $282^{\circ}$ del Código Procesal Civil). Tal como se expresó en el acápite previo, en la Ley № 27048 -que reformuló el inciso 6 del artículo $402^{\circ}$ del Código Civil- se le reconocía solamente a la conducta procesal del demandado un valor indiciario que debía ser evaluado junto 
con las otras pruebas presentadas. La opción de la Ley № 28457 es más severa pues no sólo desprende consecuencias jurídicas de la conducta procesal de una de las partes si no que lo hace de su falta de apersonamiento al proceso. En esa medida se recorta la libertad del demandado en la medida de que se le insta compulsivamente a presentarse el proceso bajo la amenaza de declarar la paternidad que se alega respaldada en la prueba de ADN, ofrecida por la parte demandante.

La libertad es un eje estructurador del campo de los derechos humanos. De forma amplia, la libertad se refiere a la posibilidad de autodeterminación, a la capacidad de que las personas conduzcan sus vidas en la forma en que les parezca siempre que sus actos no afecten a terceras/os. El inciso a) del numeral 24 del artículo 2 de la Constitución señala que "nadie está obligado a hacer lo que la ley no manda, ni impedido de hacer lo que ella no prohíbe". El Tribunal Constitucional ha señalado que

En el Estado Constitucional, la aludida libertad natural se traduce en una libertad jurídica protegida constitucionalmente, de forma tal que todo acto orientado a limitarla debe, de modo obligatorio, encontrarse constitucionalmente justificado. Este principio medular encuentra expresión en el artículo $2^{\underline{o}}$, inciso 24, literal a), de la Constitución, conforme al cual "nadie está obligado a hacer lo que la ley no manda, ni impedido de hacer lo que ella no prohíbe"; aunque, como se ha dicho, tal obligación o prohibición legal sobre el ejercicio de la libertad, no puede ser cualquiera, sino solo aquélla que encuentre sustento en los propios valores constitucionales (2011, fundamento 19).

En concordancia con esto, señala el Tribunal que "manteniendo el legislador un amplio margen de libre configuración legal, éste encuentra en el contenido protegido de los derechos fundamentales $\mathrm{y}$, más ampliamente, en la libertad iusfundamental general del ser humano, un límite prima facie que obliga a la acción legislativa a expresarse en términos constitucionalmente razonables y proporcionados" (2011, fundamento 20). Este derecho, "sin perder de vista ese principio rector reconocido en el artículo $2^{\circ}$, inciso 24, literal a), de la Constitución, existe un derecho subjetivo fundamental que cobija en su contenido constitucionalmente protegido esta libertad general iusfundamental" (2011, fundamento 21), que sería el derecho al libre desarrollo reconocido en el inciso 1, artículo 2 de la Constitución (2011, fundamento 22).

Sobre los alcances de la libertad, el Tribunal Constitucional precisa que "la construcción de un propio sentido de vida material en ejercicio de su 
autonomía moral" tiene como límite que no afecte los derechos fundamentales de otros seres humanos, de forma que se impide:

a los poderes públicos limitar la autonomía moral de acción y de elección de la persona humana, incluso en los aspectos de la vida cotidiana que la mayoría de la sociedad pudiera considerar banales, a menos que exista un valor constitucional que fundamente dicho límite, y cuya protección se persiga a través de medios constitucionalmente razonables y proporcionales.

De esta manera, esta cláusula general de libertad "viene a equilibrar una balanza que de otro modo quedaría truncada en favor de la autoridad", pues lo que exige "es que el conflicto entre la libertad y el deber se formule precisamente en términos de conflicto constitucional, lo que debe obligar a un ejercicio de ponderación entre la libertad limitada y el bien que sirve de fundamento a la norma limitadora (2011, fundamentos 22-23).

A la luz del test de proporcionalidad se analiza, en primer lugar, la idoneidad. En el caso concreto, la finalidad constitucionalmente legítima está dada por la protección del derecho fundamental a la identidad de la niña o niño (artículo 2, inciso 1 de la Constitución) y es una medida adecuada en tanto guarda una relación de causalidad con la obtención del fin porque se declara la filiación paterna y eso garantiza el derecho a la identidad.

$\mathrm{Al}$ analizar la necesidad de la medida, debe anotarse que la declaración de paternidad es el único medio viable para garantizar la identidad en cuestión cuando los demandados no se apersonan al proceso habiendo sido válidamente notificados previamente: la amenaza de declaración de paternidad por falta de apersonamiento es la medida que incide en que el demandado se presente al proceso y así colabore con el esclarecimiento de la identidad del niño y, por otro lado, también da fundamento para presumir legalmente que si el demandado no se presenta al proceso, a pesar del apercibimiento, es porque no tiene objeción válida para refutar la paternidad. Otras medidas, como la declaratoria en rebeldía, no son equivalentes en idoneidad para lograr el fin antes señalado, pues no tienen como consecuencia la declaración de la paternidad.

Por último, en relación con el examen de proporcionalidad en sentido estricto, debe tomarse en cuenta que el derecho a la identidad de la niña o niño en juego tendría una afectación intensa, mientras que la afectación de la libertad del demandado quien no puede decidir libremente para apersonarse 
o no al proceso también puede calificarse como intensa. En ambos casos los derechos son constitucionales con un peso abstracto equivalente y existe seguridad de las premisas sobre la afectación.

En tanto el derecho a la identidad tiene como titulares a niñas, niños y adolescentes entra también en la ponderación el interés superior del niño y la niña, que es, de acuerdo con los estándares nacionales e internacionales, un derecho, un principio y una norma de procedimiento ${ }^{14}$.

Esto implica dos cosas. Por un lado, que en el caso de la infancia existe un derecho a que su interés superior sea una consideración primordial que se evalúe y tenga en cuenta al sopesar distintos intereses para tomar una decisión sobre una cuestión debatida, y que la garantía de que ese derecho se pondrá en práctica siempre que se tenga que adoptar una decisión que les afecte (Comité de los Derechos del Niño 2013, párr. 6). Por otro lado, el interés superior del niño opera como una "carga de argumentación a favor de la protección de los derechos fundamentales de las personas menores de edad, es decir, un reforzamiento del carácter prima facie de estos derechos, reconociéndoles un peso adicional a los mismos, pero sin perder su carácter de principio" (IIDH 2008, p. 39-40). Así, el interés superior de niños y niñas es un criterio para tomar en cuenta en la ponderación de derechos: implica que se prefieran las medidas que maximizan la satisfacción de los derechos de la infancia y la menor restricción de ellos (Cillero 1998: p. 12) ${ }^{15}$.

En esa medida, dado que el derecho a la investigación de la paternidad de los niños y niñas está vinculado al derecho a la identidad y al desarrollo de la personalidad, a la luz del principio del interés superior del niño, puede concluirse que la intervención que restringe la máxima satisfacción al derecho a la libertad de los demandados es constitucional.

Por su parte, la medida de intervención amerita ser analizada de cara al derecho al debido proceso. Este derecho que ha señalado el Tribunal Constitucional "se encuentra contenido en el artículo 139 inciso 3) de la Constitución" tiene "dos expresiones: la formal y la sustantiva. En la de carácter formal, los principios y reglas que lo integran tienen que ver con las formalidades estatuidas, tales como las que establecen el juez natural, el procedimiento preestablecido, el derecho de defensa y la motivación; y en su expresión sustantiva, están relacionados los

$14 \quad$ El interés superior de los niños y las niñas, incorporado a nuestra legislación inicialmente en el artículo IX del Código de Niños y Adolescentes, ha sido desarrollado en la Observación General 14 del Comité de Derechos del Niño que, en sede nacional, se ha plasmado en la Ley $\mathrm{N}^{\circ} 30466$ y su reglamento, aprobado por Decreto Supremo $\mathrm{N}^{\circ}$ 008-2018-MIMP.

15 Esto se regula específicamente en el artículo 8.3 del reglamento de la Ley $\mathrm{N}^{\circ} 30466$. 
estándares de razonabilidad y proporcionalidad que toda decisión judicial debe suponer" (2006, fundamentos 41 y 48). El derecho de defensa "garantiza que los justiciables, en la protección de sus derechos y obligaciones, cualquiera sea su naturaleza (civil, mercantil, penal, laboral, etc.), no queden en estado de indefensión" (2007, fundamento 4).

Se ha señalado que la ley materia de análisis genera una vulneración del derecho de defensa de los demandados al extraer consecuencias jurídicas de la omisión de formulación de oposición procesal por parte del demandado (Mosquera 2005: 5; Ariano 2005: 66). Sin embargo, debe recordarse que la Ley № 28457 no supone una situación de indefensión de la parte demandada pues presupone que ésta ha sido notificada válidamente y que, pese a ello y a haber recibido un apercibimiento de ser declarado padre en omisión de respuesta, el demandado no ha formulado oposición dentro del plazo legal. Esto se condice con lo señalado por el Tribunal Constitucional respecto a la conexión del derecho a la defensa con la adecuada notificación (2008, fundamentos 7-9).

Sobre el particular, en un caso concreto, el máximo órgano de control constitucional del Perú ha señalado que:

Este Colegiado, al respecto y de lo que aparece de los actuados de dicho proceso ordinario, acompañados al expediente constitucional, observa que en efecto no se cumplió en momento alguno con notificarle válidamente el mandato de declaración judicial de paternidad extramatrimonial, pues como ha quedado demostrado con la hoja de movimiento migratorio (fojas 96 del expediente principal), el recurrente estuvo ausente del país durante el período comprendido entre el 24 de junio de 1999 y el 18 de diciembre del 2009, en que retornó al suelo patrio.

[...] aun cuando ha quedado plenamente acreditado el agravio de los derechos de la parte recurrente, no se puede tampoco y sin más desproteger los derechos constitucionales de la menor P.N.M.L. en cuanto beneficiaria de la declaración judicial de paternidad ya que ello podría resultar particularmente pernicioso en relación con su derecho a la identidad. En tales circunstancias y a efectos de obrar en forma adecuadamente previsora, esto es, compatible con el control de intensidad, deberá suspenderse los efectos nulificantes que pudieran recaer específicamente sobre el reconocimiento de paternidad ordenado en el proceso subyacente [...], hasta que culmine el nuevo trámite de dicho proceso, pues el efecto retroactivo de la presente decisión constitucional necesariamente implicará que el juez reanude los actos de notificación del mandato judicial de paternidad, siendo 
evidente que se mantendrá la expectativa de que se demuestre la filiación de la menor. Mientras ello se dilucide, la menor favorecida con la declaración del citado proceso tendrá plenamente garantizado su derecho a la identidad (2012, fundamentos 5 y 22).

En el mismo sentido, debe entenderse que no existe afectación del derecho de defensa pues no existe indefensión si el demandado tiene la posibilidad de contradecir la paternidad que se le imputa presentándose al proceso. El Estado no debe tutelar en forma adicional la opción de una persona de no intervenir en el proceso en el que ha sido demandada y que, con ello, asume la consecuencia legal que le ha sido adecuadamente anunciada.

Respecto de la segunda medida de intervención, la imposición legal de la declaración de la paternidad por la sola negativa de colaboración con la prueba de $\mathrm{ADN}$, la argumentación es similar a la desarrollada respecto de la primera medida. Con la declaración de paternidad por la falta de colaboración para la realización de la prueba de ADN se conmina la libertad del demandado imponiéndole una obligación. Sin embargo, la medida es idónea porque está orientada a una finalidad legítima que es la garantía del derecho fundamental a la identidad de la niña o niño y es adecuada en tanto sirve porque se declara la filiación paterna y eso garantiza el derecho a la identidad.

Analizando la necesidad, la declaración de paternidad es el único medio viable para garantizar la identidad en cuestión cuando los demandados no colaboran con la prueba de ADN: como se ha detallado previamente, con los cambios introducidos por la Ley № 27048, la sola disposición de que la falta de colaboración con la prueba de ADN sería evaluada por el órgano jurisdiccional no garantizaba la declaración de la filiación pese a que la negativa del demandado era respecto a una prueba que tiene un $99.9 \%$ de confiabilidad. Por ello, la negativa de colaboración debe ser valorada con mayor severidad. Los casos tramitados bajo la vigencia de la № 27048 evidenciaron un patrón de conducta de los demandados de negarse a colaborar con la prueba para evadir que se declare su condición de padres, sin que esto pudiera ser ponderado como una prueba de esa condición: sólo por la omisión del ejercicio del derecho de oposición del padre o de su negativa injustificada a realizarse la prueba se hacía impracticable por completo el derecho a la identidad de niñas, niños y adolescentes. Otra alternativa idónea como la toma obligatoria de muestras supondría una intervención más grave no sólo en la libertad de los demandados, sino en su integridad personal.

Por último, en relación con el examen de proporcionalidad en sentido estricto, como en la primera medida puede afirmarse que la garantía del 
derecho a la identidad de la niña o niño en juego es un interés que reviste mayor importancia en el caso concreto que la conminación de la libertad del demandado para someterse a la prueba.

Respecto dela tercera medida deintervención, referida a la configuración del proceso que privilegia la prueba de ADN como único medio de defensa, es pertinente analizar la medida con relación al derecho a la prueba:

Existe un derecho constitucional a probar, aunque no autónomo, que se encuentra orientado por los fines propios de la observancia o tutela del derecho al debido proceso. Constituye un derecho básico de los justiciables de producir la prueba relacionada con los hechos que configuran su pretensión o su defensa. Según este derecho, las partes o un tercero legitimado en un proceso o procedimiento, tienen el derecho a producir la prueba necesaria con la finalidad de acreditar los hechos que configuran su pretensión o defensa. Así, por ejemplo, el artículo $188^{\circ}$ del Código Procesal Civil establece que los medios probatorios tienen por finalidad acreditar los hechos expuestos por las partes, producir certeza en el juez respecto de los puntos controvertidos y fundamentar sus decisiones. Se trata de un derecho complejo que está compuesto por el derecho a ofrecer medios probatorios que se consideren necesarios, a que estos sean admitidos, adecuadamente actuados, que se asegure la producción o conservación de la prueba a partir de la actuación anticipada de los medios probatorios y que estos sean valorados de manera adecuada y con la motivación debida, con el fin de darle el mérito probatorio que tenga en la sentencia. La valoración de la prueba debe estar debidamente motivada por escrito, con la finalidad de que el justiciable pueda comprobar si dicho mérito ha sido efectiva y adecuadamente realizado (2005, fundamento 15$)$.

En la medida de que el derecho a probar es un mandato de optimización en tanto se debería garantizar en la mayor medida posible existe una intervención porque la Ley № 28457 limita el proceso sólo a la prueba de ADN que es el único medio de defensa. La idoneidad de la medida está dada por la protección del derecho a la identidad de la niña o niño y porque la prueba de ADN es el medio indicado para tal efecto pues es una prueba científica que establece con un $99.9 \%$ de confiabilidad la maternidad y paternidad biológica de una persona. Este hecho justifica para la determinación de la paternidad que prueba de este tipo sea la empleada por brindar el máximo grado de confiabilidad.

La necesidad de la medida también está justificada por las características de la prueba de ADN respecto de la filiación: al ser un dato 
de la realidad que las relaciones sexuales no siempre se dan en el marco de relaciones de pareja con características de permanencia, sino que se generan también en relaciones sexuales únicas o esporádicas en no pocos casos, es mínima la existencia de elementos probatorios que den cuenta de los encuentros sexuales durante el periodo de la concepción que permitan inferir la paternidad $y$, aunque existieran, son de una idoneidad menor que la prueba de ADN para establecer la filiación.

En el examen de proporcionalidad en sentido estricto debe señalarse que el medio escogido, la prueba de ADN, permite optimizar el derecho de defensa de la forma más idónea y, a la vez, optimiza el derecho a la identidad biológica del/a niño/a en cuestión. En esa medida, la afectación al derecho a probar es leve, mientras que el derecho a la identidad de la niña o niño en juego tendría una satisfacción intensa. En ambos casos los derechos son constitucionales con un peso abstracto equivalente y existe seguridad de las premisas por la validez de la prueba. Si a esto se suma la consideración del interés superior de niños y niñas entonces se concluye que la medida prevista en la ley es constitucional.

Entre las críticas a la normativa, Eugenia Ariano ha sostenido que la ley en mención es el resultado del "halo de infalibilidad" y critica que hayamos "regresado a la prueba plena legal. Ergo, ya no más apreciación conjunta y razonada de la prueba, ya no mas motivación del porqué se resuelve en un sentido o en otro pues quien decide es el laboratorio" (2005: 67). Al respecto, debe recordarse que la prueba del $\mathrm{ADN}$ es una prueba de afirmación de la filiación que permite establecer con casi certeza la maternidad y paternidad biológica de una persona. Este hecho justifica que el juez deba orientarse indefectiblemente por los resultados de dicha prueba pues en la determinación de la filiación, realidad de carácter científico, una prueba de este tipo ofrece el máximo grado de confiabilidad. Al respecto, Varsi señala:

El juzgador no puede reemplazar al técnico e incursionar en un terreno tan espinoso y vedado para el derecho como es la transmisibilidad de los marcadores genéticos, desestimando los principios biológicos en los que se sustente el informe pericial. Sin duda la palabra del especialista no puede ser considerada cosa juzgada, pero tampoco podemos negarle que en gran medida lo es. El ADN se convierte en una prueba de indiscutible valor en la decisión judicial [...] (2004: 3).

En la configuración de nuestro ordenamiento procesal la pericia sirve para ayudar y colaborar con el juez y se entiende que no determina el resultado de un juicio pues sólo aporta pautas para la decisión final. En 
este sentido, la pericia es un medio de prueba insuficiente para permitir una decisión judicial acertada y determinante. Sin embargo, como anota Enrique Varsi, esta concepción de la pericia es inapropiada si se intenta aplicar a pruebas científicas como el ADN pues ésta es una prueba que determina con un altísimo grado de confiabilidad la verdad a esclarecer en el proceso de filiación; el juez no debe discutir su valor pues no puede concluir por otros medios una verdad distinta, los resultados son irrefutables (2002: 2425). Ciertamente ha de resguardarse que la autoridad estatal que tiene las funciones de fiscalización de los laboratorios clínicos en los que se hacen las pruebas de ADN intervenga efectivamente para asegurar las normas de seguridad e inviolabilidad que garantizan los correctos resultados de dichos peritajes; sin embargo, no se muestra razonable de acuerdo al carácter altamente técnico de la pericia y a su alto grado de confiabilidad el que el órgano jurisdiccional pretenda variar los resultados de una realidad biológica que no está en la capacidad de determinar de manera más segura.

Respecto de la cuarta medida de intervención, referida a la imposición legal de la carga de la prueba al demandado, la decisión tiene un fin legítimo que es hacer efectivo el derecho a la identidad de los niños, niñas y adolescentes en el tiempo breve y, así, propiciar también la efectiva igualdad de responsabilidades familiares entre padres y madres. Asimismo, existe una relación lógica entre la medida y el fin buscado: si el demandado tiene recursos para pagar la prueba de ADN, con el mérito de ésta se resolverá el conflicto y se dilucidará la paternidad; la idoneidad de la medida está justificada.

En cuanto a la necesidad, ¿era la medida la única medida posible para lograr el fin de la realización de la prueba del ADN que dilucidela paternidad? En abstracto, la respuesta es negativa porque el Estado debería asumir su obligación de garantía del derecho a la identidad disponiendo, por ejemplo, la intervención del Instituto de Medicina Legal del Ministerio Público o en su defecto de la Dirección de Criminalística de la Policía Nacional del Perú, en atención a las facultades que les confiere el artículo $4^{\circ}$ de la Ley Orgánica del Poder Judicial (Ramírez 2007). No obstante, la previsión de una regla general de ese tipo implica una importante inversión presupuestaria inexistente. En esa medida, no es viable que el Estado peruano asuma el costo de la gran cantidad de procesos de declaración judicial de paternidad extramatrimonial con lo que dicha posibilidad no es una alternativa a la medida adoptada.

Así, en relación con la proporcionalidad en sentido estricto, debe tomarse en cuenta que la afectación al derecho a la defensa del demandado es intensa porque se invierte la carga de la prueba y se deposita en él la 
generación de esta. Por otro lado, el derecho a la identidad de la niña o niño en juego tendría también una afectación intensa si es que no se realiza la prueba de ADN ante la oposición del demandado. En ambos casos, los derechos son constitucionales con un peso abstracto equivalente y existe seguridad de las premisas sobre la afectación. Si bien la ponderación del interés superior del niño y la niña genera argumentos mayores a favor de la constitucionalidad de la norma, es posible establecer la regla condicionada para reforzar la constitucionalidad de la medida: que la atribución de la paternidad será constitucionalmente legítima en general, salvo que el demandado se encuentre en condición de pobreza o pobreza extrema y, por tanto, esté imposibilitado de reunir el monto del costo de la prueba de ADN aún en el plazo ampliado previsto por medio de la Ley $\mathrm{N}^{\circ} 30628$. En estos casos, el órgano jurisdiccional debería ordenar la realización de la prueba en los laboratorios públicos, aunque ello repercuta en una extensión excepcional del plazo de resolución de la filiación. Una regla interpretada de este tipo garantiza de forma menos intensa el derecho de defensa de la parte demandada expuesta a la vulnerabilidad propia de la pobreza.

Por otro lado, contra las medidas contempladas en la Ley № 28457 , en concreto contra la segunda referida a desprender consecuencias jurídicas de la negativa de colaborar con la prueba de $A D N$, se ha señalado que vulnerarían los derechos a la integridad física y a la intimidad de los demandados (Varsi 2006: 75-76, 79-82). Contra esto cabe precisar que el derecho a la integridad contraviene intervenciones en la estructura orgánica de las personas (Tribunal Constitucional 2005b, fundamento 9) y que la Ley № 28457 no implica intervención corporal alguna. Sobre el derecho a la intimidad que se define el derecho a un espacio personal "constituido por los datos, hechos o situaciones desconocidos para la comunidad que, siendo verídicos, están reservados al conocimiento del sujeto mismo y de un grupo reducido de personas, y cuya divulgación o conocimiento por otros trae aparejado algún daño" (2005, fundamento 38) cabe precisar que los vínculos de filiación no pueden considerarse un tema privado pues pertenecen al ámbito de las relaciones familiares, las que el Estado tiene especial interés en proteger ${ }^{16}$. En todo caso, el Tribunal Constitucional ha señalado que aún una intervención corporal con miras a realizar una prueba de ADN en el ámbito de un proceso penal para esclarecer la comisión de un delito es constitucionalmente admisible (2009, fundamentos 10-12).

16 La Constitución Política del Perú en su artículo $2^{\circ}$, inciso $1^{\circ}$ establece el derecho fundamental de toda persona a su identidad y el artículo $4^{\circ}$ señala que "la comunidad y el Estado protegen especialmente al niño, al adolescente, a la madre [...] en situación de abandono". En el mismo sentido, también el artículo $4^{\circ}$ de nuestra Carta Magna explicita que el Estado protege de la familia, y en ello está implícito que protege también a las relaciones familiares que surgen en ese marco. Por último, en el artículo $6^{\circ}$, queda explícito también que es política del estado difundir y promover la paternidad y la maternidad responsables. 
Asimismo, se ha argumentado desde la doctrina que esta medida vulneraría el derecho a no declarar contra uno/a mismo/a en tanto que la negativa de un varón a someterse a una prueba biológica no implica un reconocimiento ficto de paternidad, no puede usarse como presunción contra quién rehusó la prueba, ni debe acumularse indiciariamente como elemento adicional a otras pruebas rendidas en el juicio (Bidart 1997: 239246). El derecho a no autoincriminarse supone que:

el Estado está prohibido de ejercer violencia psíquica o física sobre el inculpado o acusado y ejecutar métodos engañosos o de naturaleza análoga que pudieran estar destinados a obtener involuntariamente información sobre los hechos criminales por los cuales se le investiga o acusa en un proceso penal. Del mismo modo, si el derecho a no autoincriminarse comprende el derecho a guardar silencio, en el ámbito jurisdiccional, los jueces y tribunales tienen la obligación de no asumir una aceptación tácita del silencio, pero sí a darle un sentido interpretativo del mismo que pueda ayudar a dilucidar la causa (2006b, fundamento 276).

Aunque este derecho es de aplicación en el ámbito penal, íntimamente ligado a la prohibición de la tortura y los tratos crueles, inhumanos y degradantes, conviene precisar que desprender consecuencias jurídicas del silencio del demandado en contra de sus intereses se justifica con la argumentación desarrollada en torno a la intervención en la libertad de este y de su derecho de defensa. Por lo demás, el Tribunal Constitucional ha señalado que es constitucional la toma de muestras de ADN aún cuando éstas pudieran no sólo perjudicar el estatus de culpabilidad del demandado, sino que incluyan intervenciones corporales (2009).

Una última aproximación crítica es que, regularmente, el análisis de constitucionalidad se centra en la dicotomía entre los derechos del demandado en relación con los derechos del/a niña/o cuya filiación está en discusión, descuidando el análisis de la dicotomía entre los derechos del demandado y los derechos de la demandante afectados si se ponen trabas a las demandas de filiación.

En la determinación de la filiación extramatrimonial no hay dos, sino tres intereses en juego: el del presunto padre, el de la madre y el del niño o niña. La omisión de las mujeres dentro del análisis de constitucionalidad desconoce que, en los casos concretos, cuando se obstaculiza la declaración judicial de paternidad de los/las hijos/as extramatrimoniales se refuerza el rol de la mujer como cuidadora y proveedora exclusiva de las necesidades de 
los hijos e hijas. Si no hay paternidad establecida entonces la única filiación emplazada es la materna y con eso se concentra en las mujeres el cumplimiento de las responsabilidades familiares de la crianza con la carga patrimonial y emocional que ello implica. Eso configura una violación del mandato de no discriminación por sexo. No enfocar el análisis de proporcionalidad también en relación con los derechos de las mujeres genera consecuencias discriminatorias por resultado o de discriminación indirecta (Ramírez 2009: 2). Esto se produce cuand o de "tratamientos que formalmente no son discriminatorios se derivan, por las consecuencias fácticas que tienen lugar entre personas de diverso sexo, consecuencias desiguales perjudiciales" (Villanueva 1999: 21) o, en otras palabras, cuando "la medida adoptada no necesariamente se orienta a diferenciar o dar un tratamiento jurídico desigual y perjudicial a las mujeres, pero en la práctica tal resultado se produce debido a las condiciones sociales, económicas o de otra índole que rodean al colectivo mujeres" (Alvites 2011: 131). Una mirada de este tipo "permite evidenciar situaciones fácticas en las que éstas impactan negativamente en los derechos de las mujeres" (Alvites 2011: 132).

\section{A MODO DE CONCLUSIÓN}

El sistema peruano de declaración de la paternidad extramatrimonial ha sido históricamente uno de tipo cerrado de modo que existían supuestos claramente excluidos de esta habilitación: las maternidades derivadas de relaciones sexuales esporádicas o aquellas que son producto de relaciones sentimentales que no encajan en la definición de un concubinato (por ejemplo, las relaciones entre enamorados/as o las relaciones de 'amantes'). Esa regulación restrictiva revela un sesgo intencional que excluía las relaciones afectivas consideradas valorativamente reprochables, lo que tenía repercusiones negativas en los derechos fundamentales de las hijas e hijos cuya filiación paterna no estaba determinada y que, además, era una forma de discriminación indirecta en razón del sistema sexo-género.

Con los sucesivos cambios normativos, se democratizó el acceso a la justicia para la garantía de los derechos de mujeres, hijas e hijos relacionados asociados a la declaración legal de la filiación paterna. A la luz de los cambios materiales y procesales aprobados, en la práctica el sistema peruano de investigación de la paternidad es uno de tipo abierto, si bien en el plano formal se trata de un sistema mixto por yuxtaposición.

Este trabajo plantea que las modificaciones planteadas al proceso de declaración judicial de paternidad son constitucionales a la luz del test de proporcionalidad. No obstante, se considera que es un reto para 
el Estado peruano reforzar la garantía del derecho a la identidad y de las responsabilidades familiares compartidas, así como el derecho a la defensa, en un contexto de pobreza que afecta a una parte importante de la población del país. Todos los derechos 'cuestan' y, aún así, todas las personas tienen derecho a su garantía, particularmente las niñas, niños y adolescentes. El rol de las juezas y jueces en la administración sustantiva de los valores de la justicia es el reto más importante en cada caso concreto que sea resuelto en el marco normativo vigente.

\section{REFERENCIAS}

Alvites Alvites, Elena (2011). Derecho constitucional y métodos feministas. La interpretación del derecho a la igualdad y a la no discriminación para la protección de los derechos de las mujeres. Fernandez Revoredo, Marisol y Félix Morales Luna (coordinadores). Métodos feministas en el Derecho. Aproximaciones críticas a la jurisprudencia peruana. Lima: Palestra.

Ariano Deho, Eugenia (2005). El nuevo proceso de declaración de filiación extramatrimonial ¿vanguardismo o primitivismo procesal?. Actualidad Jurídica. Lima, número 134, pp. 65-68.

Bernal Pulido, Carlos (2007). El principio de proporcionalidad y los derechos fundamentales. $3^{\text {a }}$ edición. Madrid: Centro de Estudios Políticos y Constitucionales.

Bernal Pulido, Carlos (2005). La ponderación como procedimiento para interpretar los derechos fundamentales. En Enrique CÁCERES, Imer B. FLORES, Javier SALDAÑA y Enrique VILLANUEVA (coordinadores). Problemas contemporáneos de la Filosofía del Derecho. México: Universidad Nacional Autónoma de México, pp. 17-35.

Bidart Campos, Germán José (1997). La negatoria a someterse a pruebas biológicas en el juicio de filiación. Diálogo con la Jurisprudencia. Lima, número 5, año 3, pp. 239-246.

Cillero Bruñol, Miguel (1998). El interés superior del niño en el marco de la Convención internacional sobre los derechos del niño. En GARCÍA MÉNDEZ, Emilio y Mary BELOFF (compiladores). Infancia, ley y democracia en América Latina análisis crítico del panorama legislativo en el marco de la Convención Internacional sobre los derechos del niño (1990-1999). Bogotá: Ed. Temis/Desalma. Recuperado de: < http://www.iin.oea.org/el_interes_superior.pdf > 
Comité de los Derechos del Niño. Observación General $N^{\circ} 14$ sobre el derecho del niño a que su interés superior sea una consideración primordial (artículo 3, párrafo 1), CRC/C/GC/14, 2003.

Cornejo Chavez, Héctor (1999). Derecho Familiar Peruano. Décima edición. Lima: Gaceta Jurídica.

Espinoza Espinoza, Juan (2010). Las actuales coordenadas en materia de declaración judicial de filiación extramatrimonial. Foro Jurídico, número 10, pp. 60-70.

Espinoza Espinoza, Juan (2005). Los principios contenidos en el Título Preliminar del Código Civil Peruano de 1984. Análisis doctrinario, legislativo y jurisprudencia. 2da edición. Lima: Fondo Editorial de la Pontificia Universidad Católica del Perú.

Espinoza Espinoza, Juan (2002). El interés superior del menor frente al "interés superior del presidente". Sobre acrobacias interpretativas y otros malabares jurídicos para justificar ambos principios. Diálogo con la Jurisprudencia. Lima, Año 8, número 47, pp. 29-40.

Fernández Revoredo, Marisol (2011). Derecho de Familia y métodos feministas. En Fernandez Revoredo, Marisol y Félix Morales Luna (coordinadores). Métodos feministas en el Derecho. Aproximaciones críticas a la jurisprudencia peruana. Lima: Palestra, pp. 183-205.

Fernandez Rodriguez, José Julio (2007). La justicia constitucional europea ante el siglo XXI. $2^{a}$ edición. Lima: Tecnos.

Instituto Interamericano de Derechos Humanos. (2008). Manual Autoformativo en Acceso a la Justicia y Derechos de la Niñez y Adolescencia en Centroamérica. San José: IIDH.

Landa Arroyo, César (2003). Tribunal Constitucional y Estado democrático. $2^{a}$ edición. Lima: Palestra.

Lloveras, Nora y Olga Orlandi (2007). El derecho del niño a la identidad filiatoria y su reafirmación por la Corte Suprema de Justicia del Perú. Nota al fallo sobre constitucionalidad de la Ley № 28457 que regula el proceso peruano de filiación judicial de paternidad extramatrimonial. JUS Jurisprudencia. Lima, número 6, pp. 37-44. 
Liési Thurler, Ana (2007). Un fenómeno latinoamericano en el siglo XXI. Intentos de inconstitucionalizar iniciativas legislativas dirigidas a la superación del sexismo. JUS Jurisprudencia. Lima, número 6, pp. 73-79

Martel Chang, Rolando (2005). Proceso de filiación por paternidad extramatrimonial. Pasando de un extremo a otro. Actualidad Jurídica. Lima, número 138, pp. 67-70.

Mosquera Vasquez, Clara Celinda (2005). La Ley № 28457 y los nuevos procesos de filiación. Legal Express. Lima, Año 5, número 54, p. 5.

Plácido Vilcachagua, Alex (2005). 'Creditur virgini pregnati...', volviendo al ancien droit: a propósito de la Ley № 28457 que regula el proceso de filiación judicial de paternidad extramatrimonial. Actualidad Jurídica. Lima, número 134, pp. 33-44.

Ramírez Huaroto, Beatriz (2011). Demagogia e inacción estatal. Derechos fundamentales y la carga de la prueba en los procesos de declaración judicial de paternidad extramatrimonial. Gaceta Constitucional, número 43, pp.339-351.

Ramírez Huaroto, Beatriz (2009). Paternidades negadas: aplicación del enfoque de género a las normas peruanas de investigación de paternidad extramatrimonial. Ponencia presentada en el Encuentro Académico Latinoamericano de Justicia, Género y Sexualidad. Santiago de Chile.

Ramírez Huaroto, Beatriz (2007). ¿Qué puedo hacer si el padre de mi hija o hijo no quiere reconocerlo? Análisis de constitucionalidad de la Ley № 28457 desde la perspectiva de género. Derecho Virtual. Año II, número 4, marzo-junio 2007.

Tribunal Constitucional (2011). Sentencia en el Expediente № 000322010-PI/TC, de fecha 19 de julio de 2011.

Tribunal Constitucional (2009). Sentencia en el Expediente № 008152007-PHC/TC, de fecha 7 de diciembre de 2009.

Tribunal Constitucional (2008). Sentencia en el Expediente № 027282007-AA/TC, de fecha 9 de julio de 2008.

Tribunal Constitucional (2007). Sentencia en el Expediente № 066482006-PHC/TC, de fecha 14 de marzo de 2007. 
Tribunal Constitucional (2006). Sentencia en el Expediente № 000232005-AI/TC, de fecha 27 de noviembre de 2005.

Tribunal Constitucional (2006). Sentencia en el Expediente № 0032005-PI/TC de fecha 9 de agosto de 2006

Tribunal Constitucional (2005). Sentencia en el Expediente № $06712-$ 2005-HC/TC, de fecha 17 de octubre de 2005.

Tribunal Constitucional (2005b). Sentencia en el Expediente № 049032005-PHC/TC, de fecha 8 de agosto de 2005.

Varsi Rospigliosi, Enrique (2007). La decisión de la Corte Suprema de Justicia del Perú acerca de la declaración judicial de la paternidad extramatrimonial. De las defensas tontas y los padres cobardes. Jus Jurisprudencia, número 6, pp. 15-18.

Varsi Rospigliosi, Enrique (2006). El proceso de filiación extramatrimonial. Lima: Gaceta Jurídica.

Varsi Rospigliosi, Enrique (2004). ADN: Génesis del hombre y espíritu de la filiación. Cuadernos Jurisprudenciales. Lima, Año 4, número 37, pp. 3-18.

Varsi Rospigliosi, Enrique (2002). La filiación ¡no es cuestión de sexo, es cuestión de piel!. Diálogo con la jurisprudencia. Lima, Año 8, número 40, pp. 19-34.

Varsi Rospigliosi, Enrique (1999). Filiación, derecho y genética: aproximaciones a la teoría de la filiación biológica. Lima: Universidad de Lima. Fondo de Cultura Económica.

Villanueva Flores, Rocío (1999). Análisis del derecho y perspectiva de género. AA.VV. Sobre género, derecho y discriminación. Lima: Defensoría del Pueblo.

Fecha de recepción : $\quad 31$ de agosto de 2018

Fecha de aceptación : : 26 de octubre 2018 